ISSN 0258-7122 (Print), 2408-8293 (Online)

Bangladesh J. Agril. Res. 43(1): 25-38, March 2018

\title{
GENETIC DIVERSITY BASED ON AGRONOMIC AND FRUIT QUALITY TRAITS IN GBOMA EGGPLANT (Solanum macrocarpon L.)
}

\author{
O. T. AdENIJI ${ }^{1, *}$, P. M. KUSOLWA ${ }^{2}$ AND S. W. O. M. REUBEN ${ }^{3}$
}

\begin{abstract}
Solanum macrocarpon $\mathrm{L}$ is a fruit and leaf vegetable in sub-Sahara Africa. The genetic diversity of the crop remains largely unexploited consequently there is a dearth of genetic information on agronomic and fruit quality traits. Agronomic and fruit quality variability and association among traits were evaluated. Twenty - six accessions were grown in a randomized complete block design with three replications. Measurements taken on agronomic and fruit quality traits were subjected to a combined analysis of variance, Principal Component Analysis and grouping using Unweighted Pair Group Method Arithmetic Average using option Ward's. There were significant differences $(\mathrm{P} \leq 0.05)$ among the accessions for all the traits, while Genotype by Year Interaction (GYI) showed insignificant effects for most traits except plant height at flowering and maturity and seed yield. High broad sense heritability suggested the preponderance of both additive and non-additive genetic action for agronomic and fruit quality traits. The percentage contribution of agronomic traits toward the genetic diversity was maximum in plant height at flowering and plant height at maturity. Positive correlation coefficients was recorded between days to $50 \%$ flowering and fruit infructescence/plant $(\mathrm{r}=0.45, \mathrm{P} \leq 0.05)$. Dendogram analysis revealed three distinct groups with overlap of traits and no relationship between geographic location and phenotypic diversity. Hybridization among MM 268, MM 10256, MM 150 and MM 10161 may bring together gene constellations for earliness, fruit yield and delayed time to fruit browning. Superior genotypes are recommended for use in hybridization schemes for variety development and the subsequent molecular characterization
\end{abstract}

Keywords: Diversity; Fruit infructescence per plant; Principal Component Analysis, Total Soluble Solids; Fruit browning; Fruit cluster: Solanum macrocarpon.

\section{Introduction}

Solanum macrocarpon L. (Gboma eggplant) $(2 \mathrm{n}=24)$ is classified in Solanum subgenus Leptostemonum; section Melongena and series Macrocarpa Bitter. It is cultivated throughout tropical Africa, especially in humid regions. The wild ancestor of S. macrocarpon L. is Solanum dasyphyllum Schum and Thon. The Gboma eggplant is distributed along the coast of West Africa (Ghana, Nigeria, Togo, Ivory Coast, Benin), East and South African countries (Malawi, Zambia, Zimbabwe and Mozambique) (Shippers, 2002). The species Macrocarpon

${ }^{1-3}$ Department of Crop Science and Horticulture, Sokoine University of Agriculture P.O. Box 3005, Chuo Kikuu, Morogoro, Tanzania, *Department of Crop Science and Horticulture, Federal University Oye Ekiti, Nigeria. 
comprised four cultigroups ( $S$. macrocarpon L. complex in Uganda: $S$. macrocarpon L. 'semi wild', S. macrocarpon L. 'Mukono' and S. macrocarpon L. 'Nabingo') (Bukenya and Carasco, 1994; Bukenya, and Hall, 1987). Solanum macrocarpon L. is indigenous to Africa; its production, consumption and utilization are compatible with the norms, beliefs and food culture of communities in sub Sahara Africa. Both the fruits and leaves are consumed fresh or stewed with other vegetables like Amaranth and Cabbage. Production of fruits and leaves are mainly for domestic market and export is limited. It is a perennial shrub and robust, it grows up to 1.5 meters tall, with glabrous or prickly stems. The leaves are simple, alternate and blades are large $(15-46 \mathrm{~cm} \times 8-30 \mathrm{~cm})$, stipules are absent; and the petiole grows up to $7 \mathrm{~cm}$ long (Shippers, 2002). The fruits are large (ranged from 3 to $12 \mathrm{~cm}$ in diameter and 2 to $6 \mathrm{~cm}$ long) spherical or depressed, usually cream, green, whitish or purple or with lighter markings at commercial harvest. At maturity, the fruits turn yellow or orange or brown in colour and the surface may crack (Daunay et al., 2001a, b, Collonnier et al., 2001; Adeniji, 2013).

Solanum macrocarpon L. has not attracted the interest of researchers compared to other Solanum species (Tomatoes and Peppers). As an important underutilized leaf and fruit vegetable in sub Sahara Africa, production is hindered by dearth of improved varieties, susceptibility to biotic and abiotic stresses. Genetic information on agronomic and fruit quality variation in Gboma eggplant from Africa is limited, yet agronomic variation and relatedness usually reveals important traits of interest to plant breeders and variety development (Thormann and Osborn, 1992). Prior to genetic improvement, evaluation of genetic resources was crucial for breeders to establish variation among individuals and selection of popular cultivars with reference to changes in consumer demand. Postharvest handling of fresh fruits is constrained by fruit flesh browning; this is associated with phenolic compounds in the fruit. Variation for fruit quality traits (fruit browning, fruit acidity and total soluble solids (Adeniji and Aloyce, 2012) usually depend on genetic and non-genetic factors (Bukenya and Carasco, 1994). Field evaluation of accessions from different geographical locations may provide information on traits associated with specific environment. In this study, we examined variability among accessions of $S$. macrocarpon $L$. based on agronomic and fruit quality traits, determine association among agronomic and fruit quality traits, and identify promising accessions for specific and multiple traits.

\section{Material and Methods}

Seeds of 26 genotypes of $S$. macrocarpon L. received from different parts of Africa and Asia conserved in the gene bank of The World Vegetable Center and French Institute for Agricultural Research (Table 1) were used for field and laboratory investigations. These accessions are landraces in their respective places of collection and posses agronomic and fruit quality traits that could be of 
importance for variety development in this species. The entries are homogeneous for phenotypic traits. Agronomic investigations took place at Horticultural Research and Training Institute, Tanzania $\left(4.9^{\circ} \mathrm{S}\right.$ latitude, $3.7^{\circ} \mathrm{E}$ longitude; altitude. 1290 meters), during two consecutive years between June to November, 2009 and 2010. The experimental site received annual rainfall of 700 to $1000 \mathrm{~mm}$ during trial periods; soil was a well drained clay loam and slightly acidic ( $\mathrm{pH}$ of 6.0 and 6.4). Seeds were sown in multipot seedling trays and maintained for three weeks. A randomized complete block design with three replications was used for field evaluation, each plot comprised three rows (ridges) of $7 \mathrm{~m}$ long and $0.75 \mathrm{~m}$ spacing between rows. Vigorous and healthy seedlings at 3 weeks old were transplanted to the sides of the ridges. Agronomic and fruit quality traits were measured at different stages of growth. The number of days to $50 \%$ flowering was counted as the number of days from transplanting to attainment of $50 \%$ flowering. Plant height $(\mathrm{m})$ was measured at $50 \%$ flowering and at maturity by random sampling of 15 vigorous plants per replicate. At harvest, plants in each net plot $(3 \mathrm{~m} \times 3 \mathrm{~m})$ were used to determine the number of fruits/plant, fruits/infructescence and fruit infructescence/plant. Harvested fruits from each net plot were used to determine fruits/plant and fruit yield (t/ha). Fruit weight was measured on three randomly picked fruit per plant in grams. Fruit taste was determined on a two point scale of $1=$ Bitter and $2=$ Tasty by panellist of 20 farmers and consumers. Fruit acidity $(\mathrm{pH})$ at commercial ripeness and at physiological maturity was measured by $\mathrm{pH}$ meter (meq citric acid/100 $\mathrm{ml}$ ). The time (seconds) to fruit browning after cut was determined using a stop watch. The Total Soluble Solids (TSS) was measured using hand held refractometer from ten randomly picked fruits per entry at commercial ripeness and maturity. Seed mass/plant (grams) and seed yield (t/ha) were measured using appropriate balances. A combined analysis of variance (PROC - GLM procedure of SAS, (1998) was performed using replication as a random variable to determine the level of significance and the percentage of contribution of each component to the total variation. The Genotype $(\mathrm{G})$, Year $(\mathrm{Y})$, and Genotype by Year Interaction (GYI) were considered to be fixed-effects. To estimate the magnitude of genotypic variability for traits measured, genetic variance $\left(\sigma^{2} \mathrm{~g}\right)$, phenotypic variance $\left(\sigma^{2} p\right)$, genotypic coefficient of variation $(\mathrm{GCV})$, phenotypic coefficient of variation (PCV) and broad sense heritability were estimated using the formula described by Uguru (1995). To determine the relative importance of agronomic and fruit quality traits in diversity, the principal component analysis was done prior to cluster analysis. Relationships among agronomic and fruit quality traits were studied by Principal Component Analysis (referred hereafter as PCA) (SAS, 1998) and UPGMA (Unweighted Pair Group Method Arithmetic Average) using option Ward's (Ward, 1963; Sneath, and Sokal, 1973; Sokal and Michener, 1958) for grouping. Each accession was considered as one OTU. Prior to multivariate analysis, agronomic traits were transformed to standard units (log transformation). 
Table 1: Solanum macrocarpon L. accessions used in the study organized by country of collection

\begin{tabular}{|c|c|c|c|}
\hline Acc no & Acc Code & Country of collection & Source \\
\hline 1 & S00052 & Malaysia & AVRDC \\
\hline 2 & S00013 & Unknown & AVRDC \\
\hline 3 & MM 10161 & Burkina Faso & INRA \\
\hline 4 & MM 12209 & Democratic Republic of Congo & INRA \\
\hline 5 & MM 1132 & Togo & INRA \\
\hline 6 & MM 150 & Ivory coast & INRA \\
\hline 7 & MM 872 & Madagascar & INRA \\
\hline 8 & MM 905 & Chad & INRA \\
\hline 9 & MM 714 & Zimbabwe & INRA \\
\hline 10 & MM 268 & Mauritania & INRA \\
\hline 11 & MM 10256 & Ghana & INRA \\
\hline 12 & CR001 & Cameroon & AVRDC \\
\hline 13 & MM 10181 & Burkina Faso & INRA \\
\hline 14 & CR006 & Cameroon & AVRDC \\
\hline 15 & CN 012 & Cameroon & AVRDC \\
\hline 16 & MM 1615 & Unknown & INRA \\
\hline 17 & MM 11044 & Ivory coast & INRA \\
\hline 18 & MM10351 & Madagascar & INRA \\
\hline 19 & MM 12302 & Nigeria & INRA \\
\hline 20 & MM 1127 & Benin & INRA \\
\hline 21 & MM 583 & Benin & INRA \\
\hline 22 & MM 1144 & Nigeria & INRA \\
\hline 23 & MM 10260 & Ghana & INRA \\
\hline 24 & MM 856 & Togo & INRA \\
\hline 25 & MM 10252 & Mauritania & INRA \\
\hline 26 & MM 10251 & Nigeria & INRA \\
\hline
\end{tabular}

Legend: AVRDC $=$ Asian Vegetable Research and Development Center.

INRA $=$ French Institute for Agricultural Research .

\section{Results and Discussion}

\section{Phenotypic Character Distribution}

There were significant differences $(\mathrm{P} \leq 0.05)$ among the accessions for all the traits, while for Genotype by Year Interaction $(\mathrm{GYI})$ significant $(\mathrm{P} \leq 0.05)$ and 
non-significant differences were found (Table 2) for traits. The accessions of Solanum macrocarpon L. showed large phenotypic variation (within and between years) in agronomic and fruit quality traits and mean performance. A similar trend of result was reported among Solanum aethiopicum sub groups (Adeniji, 2012) and Solanum melongena L. (Kumar and Arumugam, 2013). Insignificant Year and Genotype by Year (GY) interaction for all traits except plant height at flowering implied that environmental variables during trial periods were consistent over years of evaluation and did not influence the phenotype of the accessions. Analysis of the variance components (Table 2) showed that estimates of phenotypic variances are larger than their corresponding genotypic variances for all traits. High manifestation of phenotypic variance compared with genotypic variance indicated a larger manifestation of environmental influence on genotypes during the growing period compared to genetic factors. Similarly, phenotypic coefficients of variations were larger than the genetic coefficients of variations, except for days to $50 \%$ flowering, seed yield and fruit inflorescence per plant. High proportion of phenotypic coefficient of variation indicated that variation observed among accessions was mainly due to environmental factors rather than genetic factor. Broad-sense heritability estimates (Table 2) were high for all traits, this implied the importance of these traits for selection of promising accessions. Heritability and genetic variance obtained in this study are important for selection of potential parents from the population. The fruits/plant was highest in MM872 (33) followed by MM1144 (31), although the fruit size was small (fruit length of $1.2 \mathrm{~cm}$ and fruit diameter of $1.8 \mathrm{~cm}$ in MM 10260) and large (fruit length of $6.0 \mathrm{~cm}$ and fruit diameter of $6.1 \mathrm{~cm}$ in MM 10161) (Table 3 ). The fruit weight of three fruits per plant $(\mathrm{g})$ ranged from $14 \mathrm{~g}$ (MM 714 and MM 10161) to $173 \mathrm{~g}$ (S00052) with an average of $94 \mathrm{~g}$. Values for other accessions are intermediate between the two extremes. Four accessions (MM10161, MM11044, MM 12209 and MM1615) recorded high seed mass $(\mathrm{g}) /$ plant, on the other hand they recorded moderately low values for seed yield (t/ha). Fruit yield (t/ha) varied from 28 t/ha (S00052) to $77 \mathrm{t} / \mathrm{ha}$ (MM905, MM10260). The fruits of CR006 were long $(6.73 \mathrm{~cm}$ on the average), while MM150 were wide $(8.6 \mathrm{~cm}$ diameter). Among the entries, MM150 and MM10161 performed best for fruit size, fruit length and fruit diameter $(\mathrm{cm})$. Fruit infructescence/plant was high (4) in CR005. MM10161 was best for multiple traits (fruits/plant, seed mass (g), fruit yield (t/ha), fruit length and fruits/infructescence). At commercial harvest fruits are slightly alkaline $\left(\mathrm{p}^{\mathrm{H}}\right.$ of 6.4) in MM1615 and acidic (low $\mathrm{p}^{\mathrm{H}}$ of 5.3) in MM1132. At physiological maturity fruit $\mathrm{p}^{\mathrm{H}}$ peaked (5.7) in MM10181, but low $\mathrm{p}^{\mathrm{H}}$ reading of 4.2 in MM10181. Earliness varied among the accessions, for instance, there were accessions that flowered spanning $66 \mathrm{~d}$ (MM150) and $86 \mathrm{~d}$ (MM714 and CR005) after transplanting. The fruit browning time was early (two minutes) in CR006, S00052, MM10181 and late (five minutes) in MM1132, MM10260, MM714 and MM 1144. 


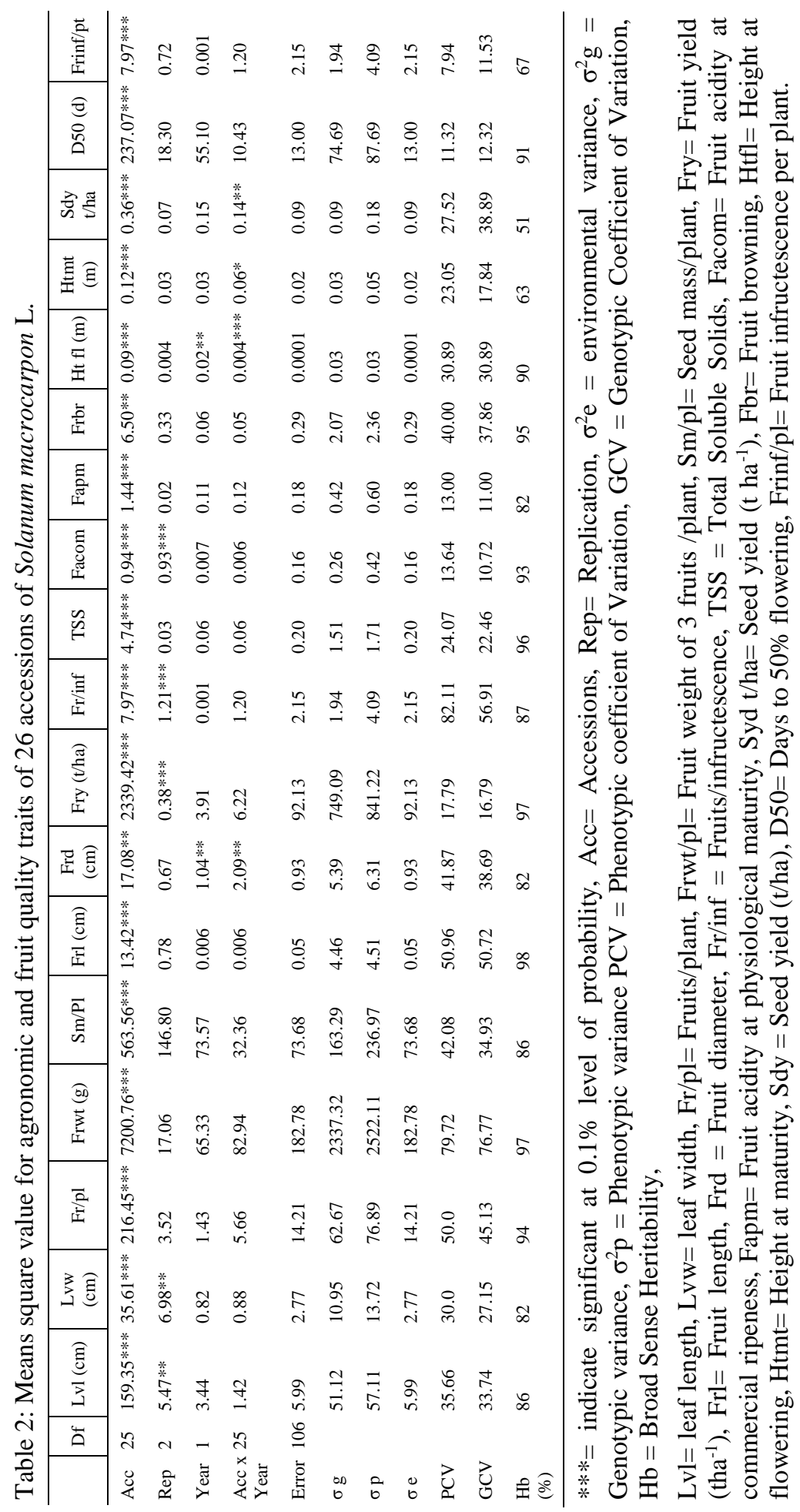




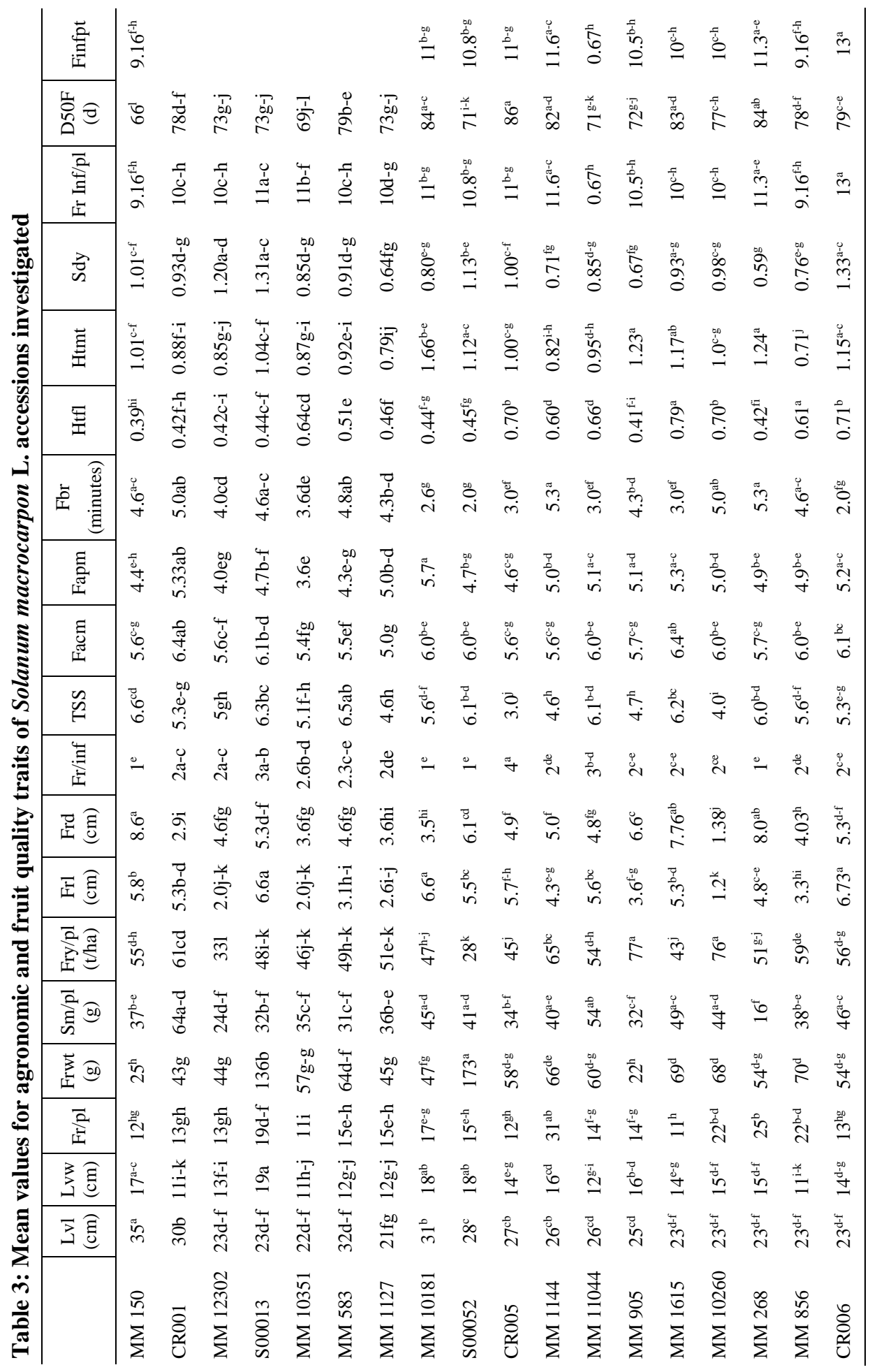




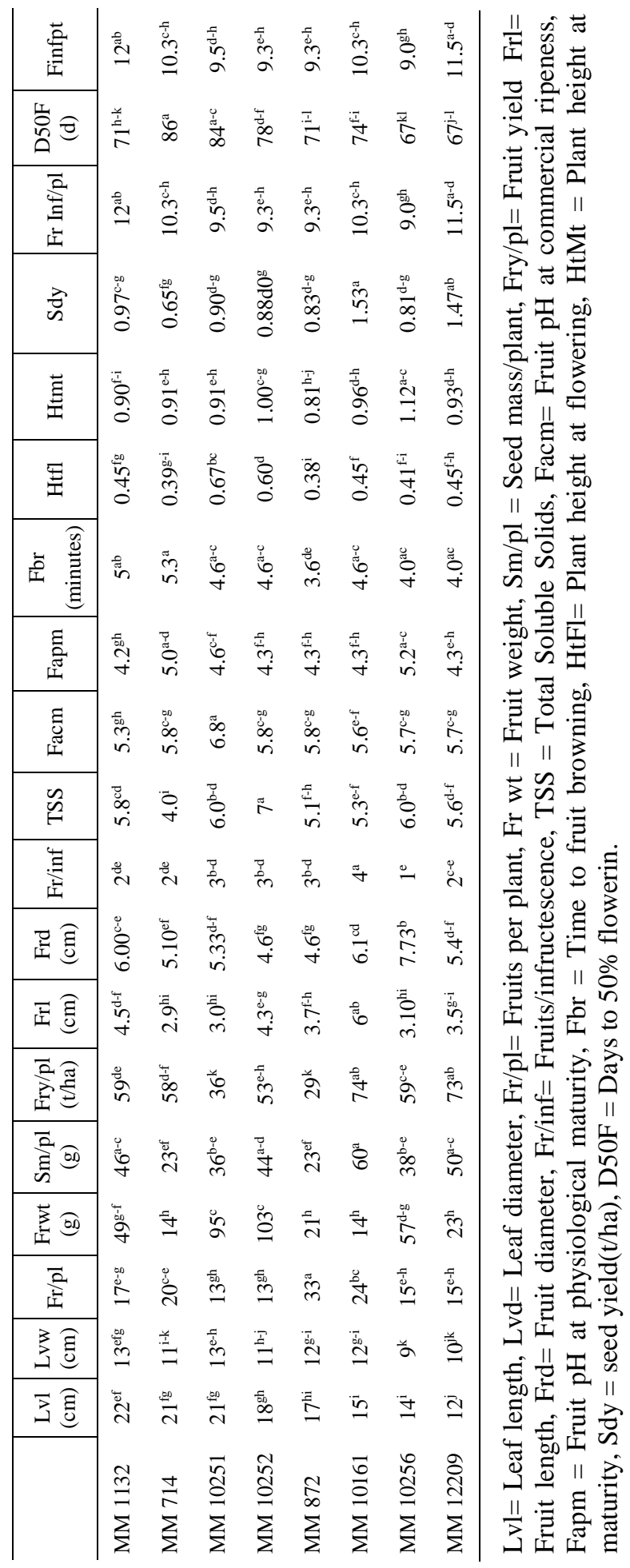




\section{Principal Component and Cluster Analysis}

The relative discriminating power as shown by eigenvalues was high for the first three principal component axes with eigenvalues in excess of 2.20 , altogether they explained $46 \%$ of the total variance (Table 4). The large number of PCs implied narrow genetic base in the population. In the pooled analysis, the percentage contribution of agronomic traits toward the genetic diversity was maximum (45\%) in plant height at flowering, followed by days to $50 \%$ flowering (37\%), plant height at maturity (36\%), fruit infructescence (34\%). This showed the discriminatory power of plant height and length of time to flowering for selection and breeding. The first PC axis demonstrated inverse relationship between plant height $(\mathrm{m})$ and seed yield $(\mathrm{t} / \mathrm{ha})$. In contrast a positive association was recorded among fruit infructescence/plant, plant height and days to 50\% flowering. The fruit browning time (seconds) recorded negative coefficient low in magnitude on the first principal component axis. The second PC axis accounted for additional $16 \%$ of the unexplained variation in first principal component axis; and demonstrated high discriminatory power and positive variation for fruit browning (seconds) and fruits/plant, both traits showed negative correlation coefficient. Traits that contributed most to the first PC (plant height at flowering, earliness, height at maturity and fruit infructescence/plant) displayed negative correlation coefficient with the major traits of the second PC axis.

The projection of accessions on the plot of PC 1 by 2 showed distance among the accessions and variables responsible for the variation. Accessions along principal component axes 1 and 2 displayed a spread of accessions into four quadrants (Figure 1). Seven accessions were projected in the first quadrant, they displayed geographic heterogeneity. The spread of accessions in this quadrant demonstrated high variation for earliness, leaf length and leaf width and fruits/plant. They recorded moderate though positive coefficients on PC axes 1 and 2. In this quadrant, MM 268 was moderately separated from other entries with maximum contribution to variability, although this variation was low compared to entries dispersed in the second quadrant. The grouping of accessions in the second quadrant showed consistence with high variability and relationship for plant height at flowering and maturity, fruits infructescence/plant and fruit acidity at commercial harvest and maturity. The accessions in the third quadrant displayed relationship for seed yield (t/ha) and fruit width (cm). MM12209 and MM10161 displayed large variation for earliness and fruit browning. The fourth quadrant displayed geographic heterogeneity and high variation for fruit browning (seconds), fruit yield (t/ha) and fruit taste. The multivariate techniques (PCA and dendrogram) detected phenotypic distinctness, similarities, and overlap of agronomic and fruit quality traits. Dispersion on the plot of PC 1 by 2 (Figure 1) is consistent with the range of variation and broad genetic base of the accessions. Plant height at flowering and length of time to flowering were attributed toward genetic distance among accessions and contributed largely to differentiation of all the genotypes into the four quadrants. The dendrogram drawn for 26 accessions 
Table 4. Eigen values and vectors for seven principal component axes estimated for agronomic and fruit quality traits among 26 accessions of Solanum macrocarpon $\mathrm{L}$.

\begin{tabular}{l|r|r|r|r|r}
\hline Traits & Prin 1 & Prin 2 & Prin 3 & Mean \pm SD & Min - Max \\
\hline Days to 50\% flowering & $\mathbf{0 . 3 7}$ & 0.14 & -0.05 & $75.8 \pm 6.49$ & $64-90$ \\
Number of filaments & 0.24 & 0.29 & $\mathbf{- 0 . 3 0}$ & $6.34 \pm 1.05$ & $5-9$ \\
Fruit diameter & -0.15 & -0.02 & 0.04 & $6.00 \pm 1.68$ & $1.38-7.00$ \\
Fruit length & 0.17 & -0.08 & 0.07 & $4.16 \pm 1.40$ & $1.20-7.89$ \\
Leaf length & 0.21 & 0.31 & -0.16 & $21.19 \pm 5.20$ & $1-37$ \\
Leaf width & 0.13 & 0.28 & -0.04 & $12.19 \pm 2.25$ & $7-21$ \\
Fruits/plant & 0.11 & $\mathbf{0 . 3 7}$ & 0.27 & $17.54 \pm 6.99$ & $9-44$ \\
Seed mass/plant & 0.11 & -0.21 & 0.17 & $36.58 \pm 11.06$ & $11-134$ \\
Fruits yield (t/ha) & -0.05 & 0.21 & $\mathbf{0 . 4 2}$ & $54.96 \pm 15.00$ & $27-88$ \\
Fruit weight & 0.02 & 0.11 & $\mathbf{0 . 4 8}$ & $163.0 \pm 0.20$ & $111-185$ \\
Fruits/infructescence & 0.20 & $\mathbf{- 0 . 3 2}$ & -0.29 & $2.46 \pm 0.50$ & $1.0-5.0$ \\
Total Soluble Solids & 0.02 & -0.03 & -0.12 & $5.43 \pm 0.97$ & $3.0-7.0$ \\
Fruit acidity at commercial harvest & 0.27 & -0.18 & 0.003 & $5.99 \pm 0.24$ & 4.07 .00 \\
Fruit acidity at physiological & 0.29 & -0.04 & 0.11 & $4.75 \pm 0.51$ & $4.0-6.00$ \\
maturity & & & & & \\
Fruit taste & -0.15 & 0.07 & $\mathbf{- 0 . 4 2}$ & $1.96 \pm 0.20$ & $1-2$ \\
Time to fruit browning after cut & -0.07 & $\mathbf{0 . 4 2}$ & -0.14 & $3.88 \pm 1.07$ & $2-6$ \\
Plant height at flowering & $\mathbf{0 . 4 5}$ & -0.12 & 0.0001 & $0.56 \pm 0.12$ & $0.34-0.80$ \\
Plant height at maturity & $\mathbf{0 . 3 6}$ & -0.09 & 0.14 & $0.97 \pm 0.20$ & $0.60-2.12$ \\
Fruits infructescence/plant & $\mathbf{0 . 3 4}$ & -0.08 & 0.04 & $4.88 \pm 1.88$ & $5-16$ \\
Seed yield (t/ha) & -0.17 & -0.21 & 0.14 & $1.09 \pm 0.56$ & $0.16-3.57$ \\
Eigen value & 3.89 & 3.32 & 2.36 & & \\
Proportion (\%) & 19 & 16 & 11 & & \\
Cumulative (\%) & 19 & 34 & 46 & & \\
\hline & & & & & \\
\hline & & & & &
\end{tabular}

(Figure 2) based on agronomic and fruit quality traits showed similarity with the ordination of the accessions on the plot of principal component axes 1 and 2 . (Figure 1). The dendrogram showed three distinct groups with overlap of agronomic and fruit quality traits within cluster and between clusters. The 26 accessions were ordered into three clusters at $15 \%$ level of phenotypic distance. The first cluster was divided into two sub - clusters ' $a$ ' and 'b', MM1144, MM856 and MM10260 to sub cluster 'a' while MM268, 10256 and MM 150 to sub-cluster 'b'. Eleven accessions starting from MM905 to MM1132 were grouped in second cluster, which was divided into 3 sub clusters. MM905, MM 1127, MM12209 to MM714 were ordered into sub cluster 'a', while MM10351, MM 12302 and 
MM872 to sub cluster ' $b$ ' and MM10161 and MM1132 were grouped in to sub cluster ' $c$ '. The third cluster was divided into two groups, CR006, MM11044, MM10252, MM1615, MM10251 and S00052 to group ' $a$ ' and CN012 and CR001 to group 'b'. MM11044 and CR005, MM1615 and MM10251, CN012 and CR001 are most related at $2 \%, 4 \%$ and $6 \%$ distance respectively. The study showed that within and between clusters accessions from different ecogeographic regions with high level of agronomic similarities and overlap were grouped, this indicated geographic heterogeneity. Similarly agronomic and fruit quality traits were not restricted to a specific geographic location. Dispersion and overlap among accessions of Solanum macrocarpon for agronomic and fruit quality traits mirrored phenotypic variation reported in this species (Shippers, 2002). The magnitude of genetic dissimilarity found among the accessions indicated that genetic improvement of earliness, fruit yield ( $t / h a)$, seed yield ( $t / h a)$, fruit taste, fruits/infructescence, fruit infructescence/plant and fruit browning will be feasible. Inter cluster hybridization will help to develop desirable segregants, for example, accessions belonging to clusters 1'b' and 2 ' $c$ ' may aggregate genes for earliness, fruit length, fruit diameter, fruits/plant, seed yield $(\mathrm{kg})$, fruit browning and fruit yield (t/ha). Similarly, inter cluster hybridization among members of cluster 1 ' $b$ ' and cluster 3 may probably develop hybrids with superior fruit diameter $(\mathrm{cm})$, seed yield $(\mathrm{kg})$, fruit yield (t/ha) and fruit browning. Plant height, fruits/ infructescence and earliness contributed most to cluster constellation and variation among accessions, these traits and are not restricted to provenance. Hybridization among clusters may evolve desirable variations upon which selection can be made for variety development.

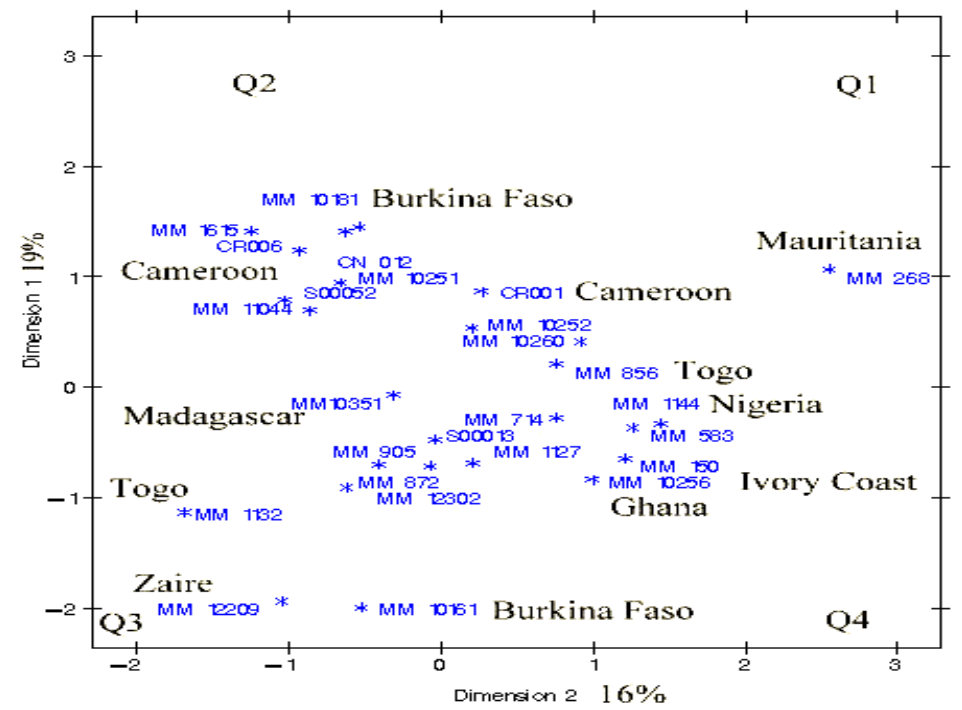

Fig. 1. Plot of the first two principal components axes showing spatial distribution of 26 accessions belonging to Solanum macrocarpon $L$. based on agronomic and fruit quality descriptors. 


Accessions
Nigeria
Togo
Ghana
Mauritania
Ghana
Ivory Coast
Chad
Benin
Zaire
Zimbabwe
Madagascar
Nigeria
Madagascar
Unknown
Benin
Burkina Faso
Togo
Cameroon
Ivory Coast
Mauritania
Unknown
Nigeria
Malaysia
Cameroon
Cameroon
Burkina Faso

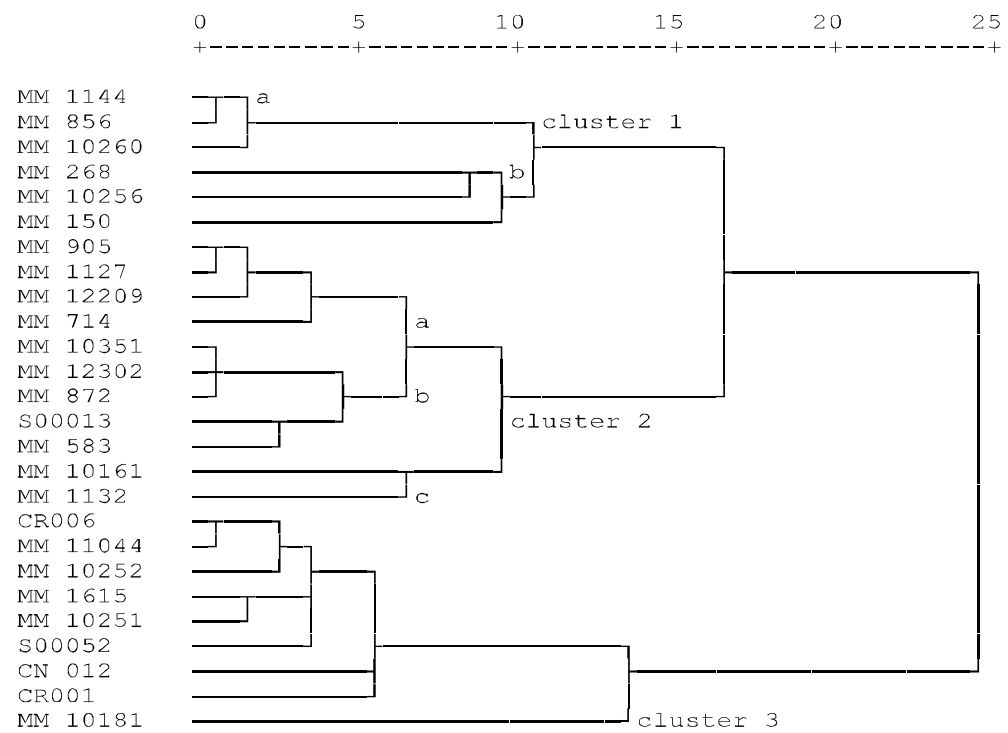

Fig. 2. Dendrogram constructed from agronomic and fruit quality data using UPGMA clustering option Ward (1963).

For genetic improvement in fruit yield, it is worthwhile to select accessions grouped in cluster 1 ' $a$ ' as donor parents. Members of cluster 1 ' $b$ ' and cluster 3 are superior for plant height; the former showed greater potential for fruit length $(\mathrm{cm})$, fruit diameter $(\mathrm{cm})$ and fruits/plant. Considering fruit infructescence/plant and plant height $(\mathrm{m})$, members of cluster 3 are potential donor parents. If genetic improvement was in favour of fruit taste (sweet) and high sugars (high $\mathrm{pH}$ value), accessions grouped in clusters 1 ' $a$ ' and 2 ' $b$ ' may be considered as donor parents. Accessions ordered in cluster 1'b' constituted early maturing group, and are donor parent for earliness, fruit length and diameter. Specific use of MM150, MM10256 (cluster 1'b') and MM12209 (cluster 2'a') as source of gene for earliness, may evolve segregating population upon which selection of maturity groups can be advanced. Members of cluster 1 ' $a$ ' and 3 are potential donor parent for delayed maturity, fruit and seed yield and direct commercialization. Distinctively MM10260 performed best for fruit yield ( $\mathrm{t} / \mathrm{ha}$ ) compared to other accessions. The absence of duplicates provided evidence that these accessions are distinct and could be conserved for future genetic studies, specifically for molecular analysis of diversity.

\section{Conclusion}

The overall importance of the investigation was related to quantification of agronomic and fruit quality diversity, identification of promising traits and accessions for genetic improvement. Both type of analyses i.e., variance component and multivariate diversity provided good insight on the magnitude of variation, similarities and distinctness among the accessions. Agronomic and 
fruit quality traits investigated showed ample variation among the accessions. The best performing accessions for single and multiple traits i.e. earliness, fruit number, fruit yield and fruit infructescence in this population evaluated were identified and potential donor parents for further genetic improvement of Gboma eggplant through hybridization.

\section{Acknowledgements}

We appreciate with thanks INRA and AVRDC, HORTI and Sokoine University of Agriculture, Tanzania for field evaluation and laboratory.

\section{References}

Adeniji, O.T 2013. Morpho-agronomic and molecular diversity among seven Solanum (Eggplant and Relatives) species and inheritance of agronomic traits Unpublished Thesis, Sokoine University of Agriculture, Tanzania. Pp. 320.

Adeniji, O.T and A. Aloyce 2012. Farmers' knowledge of horticultural traits and participatory selection of African eggplant varieties (Solanum aethiopicum L.) in Tanzania Tropicultura. 30: 3185 - 191

Bukenya, Z. R. and J.B. Hall. 1987. Six cultivars of Solanum macrocarpon L. (Solanaceae) in Ghana. Euphytica. 17(1): 91- 95.

Bukenya, Z. R. and J.F. Carasco. 1994. Biosystematic study of Solanum macrocarpon L. - S. dasyphyllum L. complex in Uganda and relations with Solanum linnaeanum. East African Agric. For. J. 59(3): 187-204.

Collonnier, C., L. V. Fock. V. Kashyap, G.L. Rotino, M.C. Daunay, Y. Lian, I.K Mariska, M.V. Rajam, A. Servaes, G. Ducreux, and D. Sihachakr 2001. Applications of Biotechnology in eggplant. Plant Cell, Tissue and Organ Culture. 65:91-107.

Daunay M.C., R.N. Lester, and G. Ano. 2001a. Cultivated eggplants. In: Tropical plant breeding. (Editedby Charrirer, A, Jacquot, M, Hamon, S. and Nicholas, D.). Oxford University Press, Oxford. Pp. 200-225.

Daunay, M. C., R.N. Lester, C.H. Gebhardt, J.W Hennart, M. Jahn, A. Frary, and S. Doganlar. 2001b. Genetic Resources of Eggplant (Solanum melongena L.) and Allied Species: A New Challenge for Molecular Geneticists and Eggplant Breeders. In Solanaceae V (Edited by Van Den Berg, R.G., Barendse, G.W. and Mariani, M.). Nijmegen University Press, Nijmegen, Netherlands). Pp. 251-274.

Kumar, S. R and T. Arumugam. 2013. Correlation and Path Coefficient Analysis for Some Yield-Related Traits in $\mathrm{F}_{2}$ Segregating Population of Eggplant International Journal of Vegetable Science. 19 (4) 334-341.

SAS 1998. SAS Users Guide: Statistics. Version 5 ed. SAS Inst. SAS institute, Gary, NC, Pp. 35 .

Shippers, R. R. 2002. African Indigenous Vegetables: An overview of the cultivated species 2002 Revised Version on CD-ROM. Natural Resources Institute, Chatham, UK. Pp. 214.

Sneath, P. H. and R.R. Sokal 1973. Numerical taxonomy. W.H. Freeman \& Co. San Francisco. Pp. 573. 
Sokal, R. R. and C.D. Michener. 1958. A statistical method for evaluating systematic relationships. University of Kansas Science Bulletin. 38:1409-1438.

Thormann, C. E and T.C. Osborn 1992. Application of RAPD technology to plant breeding. Joint Plant Breeding Symposia Series, 1 November, 1992, Minneapolis, MN, USA. Madison: CCSA/ASHS/AGA, pp. 9-11.Ward, J. H. 1963. Hierarchical grouping to optimize an objective function Journal of American Statistics Association. 58: 236-244.

Uguru, M.I. 1995. Heritable relationships and variability of yield and yield components in Vegetable Cowpea. African Journal of Crop Science. 3: 23-28.

Ward, J. H. 1963. Hierarchical grouping to optimize an objective function. Journal of American Statistics Association. 58: 236 - 244. 